\title{
The Development Research of Digital Technology in Russian Theater Stage Design
}

\author{
Ying Zheng \\ Yunnan Arts University \\ Kunming, China 650500 \\ Moscow State University \\ Lomonosov, Russia
}

\begin{abstract}
Stage art design is a creative part of drama integrated art as well as an integral part of art design and modern human design system. In the era of rapid development of informatization, profound changes have taken place in people's ideas and concepts. Advanced science and technology have broken the boundaries between various kinds of designs, which requires us to view and examine the design of stage art from the perspective of modern design. Based on many years of practical experience, the author has conducted an in-depth study on the characteristics and influence of Russian theater stage art design. Beginning with the analysis of the law of digital stage design, this paper focuses on the application of digital technology in the stage design and related literature analysis, combined with its own practical experience, to explore the digital technology in the stage of the application of the formation of high efficiency, high quality, multi-creative And many other advantages; digital technology brings new ideas and the implementation of the rules of the stage for the performance of the continuous innovation to provide more possibilities, but also for stage management, design, implementation staff to provide appropriate reference experience.
\end{abstract}

Keywords-Russian drama; stage design; digital technology; science and technology

\section{INTRODUCTION}

Russia's theater stage art history has experienced a long and tortuous process of development. From a historical point of view, classical realism dominates from the very beginning. During the October revolution, they also joined some stage art style full of emotions. In the Soviet era, due to the influence of the state ideology, there appeared "immutable" stage scenery style. After the disintegration of the Soviet Union, a large number of western cultures impacted the design style of Russian stage art, and the stage art features of diversified stage and multi-modal stage appeared. Stage set from the classical single to a variety of ways combined ${ }^{1}$.

Color is the most expressive element of art, and it can quickly and directly arouse people's emotions. In drama, viewers do not necessarily notice the colors, but they are already influenced by color and change in the viewing

Wu Guangyao. Manuscripts on Western Drama History [M] Beijing: China Theater Press, 2002. process $^{2}$. In theater, the use of color correlates with the overall mood of theater, and the combination of lights deepens this change. On the stage, the combination of different colors and lights gives a different visual experience and psychological suggestion.

With the development of society, emerging disciplines based on science and technology and the arts are gradually on the stage of history. Such disciplines are called "crossdisciplinary disciplines." Digital stage design is one of the "cross-disciplinary disciplines." Stage Design is a traditional art work to create a stage art environment. In China, the early prototype of the stage design should be the design of the traditional Chinese opera stage. Today, the rapid development of digital media, which also makes the original stage design category become extremely rich.

Today's society is an era of popular culture, people's aesthetic ideas tend to be diverse, and the art of modeling is also diversified. Digital Stage Design is a Modeling innovative art involving many aspects of music, art, architecture, electronic design and so on. Nowadays, digital technology has covered every corner of the world. Although it has not been used for a long time in stage design, it can develop rapidly and a group of highly intelligent professionals emerge ${ }^{3}$. With the development of the digital age and the constant relocation of popular culture, the stage design activities will undergo unprecedented changes with high research value.

\section{Digital TeCHNOLOgY OVERVIEW}

Digital Technology is a science and technology associated with the computer. It refers to the conversion of various information, including pictures, texts, sounds and images, into computer-recognized binary digits " 0 " and "1 "After the operation, processing, storage, transmission, dissemination, restoration of technology ${ }^{4}$. Because in the

\footnotetext{
Shen Yao Ding stage art design practice and skills [M] Beijing: Beijing Arts and Crafts Press, 2004.

Wang Hong, Chen Xiaoshen, Zhang Xingiian. Digital technology and new media communication, Communication University of China Press, August 2010, first edition.

Li Sida. Digital media art design, Tsinghua University Press, September 2009, first edition.
} 
computing, storage and other aspects of the computer with information to be encoded, compressed, decoded, etc., it is also known as digital technology, computer digital technology. Digital technology is also called digital control technology.

The rapid development of digital technology is now widely used in national defense, numerical control technology, computers, communications equipment, digital instrumentation, electronic products and education and other fields. Digital media refers to a binary form of information to record, process, disseminate, access to information carrier. These include digitized media carriers such as text, sound, graphics, images, videos and animations, logical media representing such media (encoding) and the like, and physical media for transferring, storing and displaying logical media. And Digital Technology (Digital Technology) is a computer science and technology are closely related to refers to the use of certain equipment, graphics, text, sound and image and other information into computer-readable binary digits 0 and 1 and then Computing, processing, storage, distribution and restoration of technology. Today, the boundaries between technology and art are getting blurred and getting an unprecedented blend. Into art into technology, expanding the form of artistic expression, art into the cell technology makes the technology is no longer against the people thousands of miles away. As the two converge and continue to grow rapidly, digital technologies have more opportunities to infiltrate into all walks of life. The continuous updating of technologies has brought about a more comprehensive development of artistic expression.

\section{THE RUSSIAN THEATER StAGE DESIGN}

The design style of the Russian theater is unique. The birch trees, which grow on the floor and are attached to the gray walls, and the black umbrellas grow on the birch trees, no matter how the design is interpreted, the "Chekhov" or "deed" Koff style "and the" beauty of music "and" poetic beauty "revealed in it, so that people immediately felt" Chekov "; the three walls gave a lot of space for lighting design, and the back of a recessed space Gives the director another possibility (imagine that the space can be sealed or opened $)^{5}$. These combinations are agreeable and exciting. Such "approval" and "excitement" may today exceed the cheap "create" fake pictures that we have come out of.

Today, the creative style of Russian artists presents a diverse and personalized trend of pursuit of art, perseverance and daring. Although the Russian theater art has mercilessly coerced and shocked by the tide of commercialization, artists are sticking to their art and business, and their works are still of high standard. The artists still think about real life through theater, National destiny and future.

Wang Xiaomeng. The impact of the digital age on modern Chinese art design, Art and Technology, 2013-08.

\section{The Application of Digital TeChNOLOGY IN THE STAGE DESIGN}

Digital three-dimensional stage space is the stage that includes the installation of the stage, the stage sets, stage lighting, stage audio and a series of digital modeling techniques used stage art. As with many art forms, stage design, as a kind of borderless art, also has certain rules of plastic art in this three-dimensional stage space.

The combination of modern science and art, with simple, clever way to reflect the theme, show the stage style, and impressed the audience, this is the essence of digital stage design. With respect to stage visual subject design, including stage equipment, Wu Mei scenery, its function is mainly reflected in the maximum extent to break the sense of time and space, with a visual image directly contrast the atmosphere of the drama.

Stage equipment is the basic stage, light stand, LED screen structure, sound structure and other basic stage structure. Design, it is necessary to consider safety, reliability, but also attach importance to advanced and flexible. Now, the use of CNC stage machinery stretching, shrinking, lifting, lowering, transfer combined with the traditional base station to complete the equipment placement, scene changes and scheduling programs to solve the equipment hidden, lifting and placement of any problem, Shorten the time for change of scene, realize the instant change of stage space, expand the means of program scheduling and create a new stage form. With the combination of industrial technology and stage art, installation modeling art can serve as a medium for stage performances and become an effective tool for expressing stage art. Therefore, the stage installation is the basis for the performance of the stage art and the determination of the stage space structure. Its performance plan is shown through the stage assembly drawings and the necessary written instructions.

Stage design plan is to create the stage space, stage scheduling and guidance of the general plan of the stage. Under normal circumstances, the plan is the final design plan, the director and the stage coordination, cooperation basis. As technology evolves, floor plans can be drawn using computer drawing programs. It can clearly reflect the scene, the stage and the stage props on the stage position; the director can be based on it for rehearsal and design actors walk and the stage picture arrangement; lighting design can also understand the distribution of stage space, the light of the Divide and determine the location of the fixtures.

The improvement of the index of digital technology is unmatched by the analog technology, which has a very significant effect on the precision control of the equipment and the improvement of the efficiency performance of all kinds of workings in the field. The most affected here is the digital multimedia server system, which is a new video editing and control device that has been gradually emerging in recent years. ${ }^{6}$ It can accomplish the image fusion and

\footnotetext{
6 Qu Guowu. A variety of "art space" — on 2012 CCTV Spring
} and night light and light design, Modern Television Technology, 2012-03. 
splicing functions of different video devices (such as LED screens or digital projection). The visual scene has the following characteristics: freedom of control, performance vector flexibility, brilliant images and creativity. In addition, the sound, lighting, special effects and other fields also have very significant changes. In the digital lighting control equipment, lighting network control system can expand the stage lighting space, composed of special equipment and general equipment, professional equipment generally includes access to the system conventional light console, scanner console and color changer console.

With the development of digital video technology, there are many kinds of combinations in the visual space. Besides the LED screen, the LED meteor shower landscape is also a new type of digital device.

LED strip video module, its shape is like a meteor change, its bright color, high brightness, flashing effect is like the meteor in the sky across the track, so commonly known as "meteor shower", which is the gradual rise of the figures in recent years Visual technology means it is widely used in all kinds of performances in the country. Because it is not limited by any space and can be combined flexibly like video technology, its installation method is simple and it can be controlled by using digital multimedia server diverse changes. LED strip video module system shown in "Fig. 1".

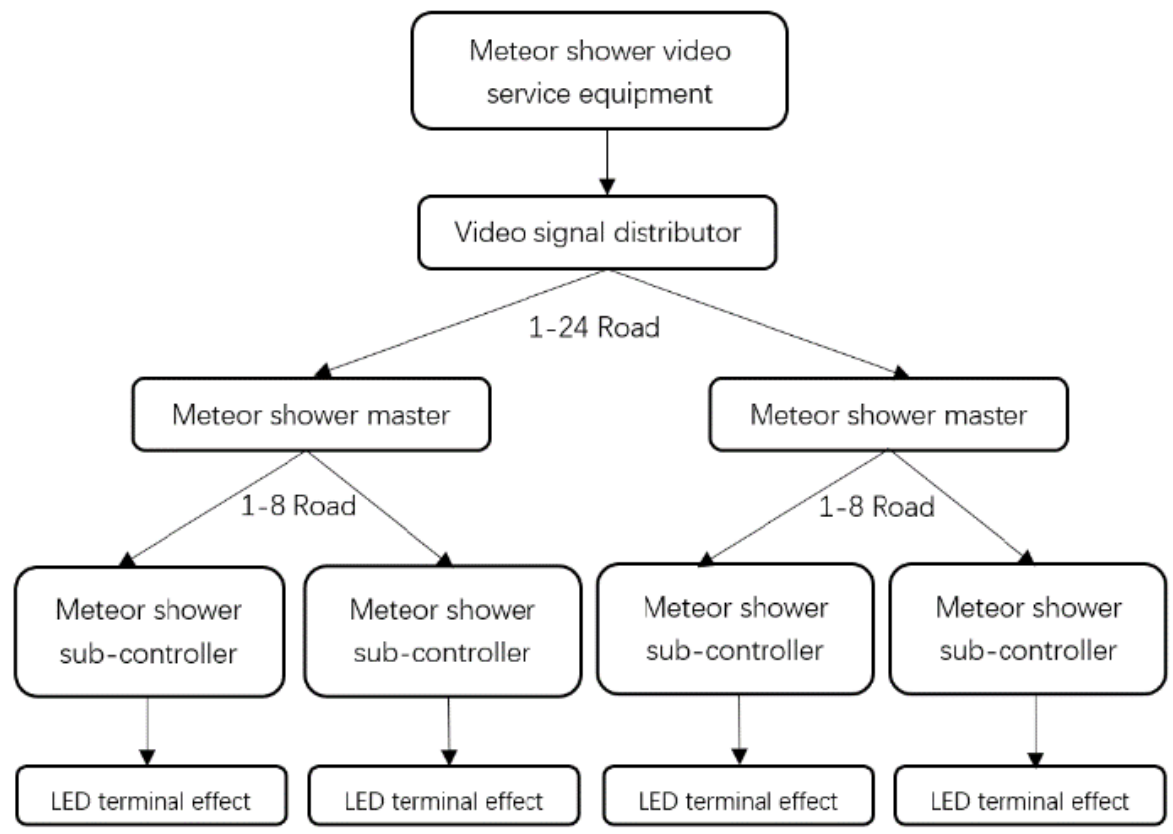

Fig. 1. LED strip video module system.

\section{Digital Technology Used in Stage Design Case STUDIES}

In order to make the scene richer, the scene of the 9th Universiade opening show uses LED meteor shower landscape design: They are divided into Seven installation, layered installation in the U-shaped front facade; three stages on both sides of the facade; yellow, Green and blue ticket area at the junction of the facade and push and pull the main screen below. Equipment program in the following "Table I":

TABLE I. EQUIPMENT PROGRAM

\begin{tabular}{|c|c|c|c|c|c|c|}
\hline Serial & Item name & Brand & Specification & Origin & Quantity & Remarks \\
\hline 1 & $\begin{array}{lll}\text { L1.5M } & \text { LED } & \text { meteor } \\
\text { shower } & & \end{array}$ & Show power & $\mathrm{L} 1.5 \mathrm{M}$ & Shenzhen & 1000 & Term of 25 days \\
\hline 2 & LED meteor & Show power & $\mathrm{L} 1.5 \mathrm{M}$ & Shenzhen & 1000 & Term of 20 days \\
\hline 3 & Distribution amplifier & Show power & & Guangzhou & 100 units & Term of 20 days \\
\hline 4 & Video server & $\operatorname{arkaos} \mathrm{A} 20$ & & Shenzhen & 4 units & Term of 20 days \\
\hline 5 & Video console & $\operatorname{arkaos} \mathrm{A} 20$ & $\begin{array}{l}\text { PEARL } \\
\text { Edition }\end{array}$ & $\begin{array}{l}\text { United } \\
\text { Kingdom }\end{array}$ & 1 unit & Term of 20 days \\
\hline 6 & Video monitor & AVOLITE & & Shenzhen & 6 units & Term of 15 days \\
\hline 7 & System connection cable & & & Shenzhen & 500 & Term of 20 days \\
\hline
\end{tabular}

The digital performance of lighting technology is mainly in two aspects. The first is the digital development of lighting equipment, which improves the speed and safety of lighting control. The second is the digital application of lighting network system, which provides the transmission speed and reliability of information capacity. Digital stage lighting equipment completely changed the traditional concept of equipment, not only the equipment itself has 
improved the technical indicators and leaps, but also to transport, installation, commissioning more convenient, so that programming, control, use more streamlined. Specific summary is as follows:

Due to the success of digital technology, the combination of Ethernet technology and lighting control technology and the systematic integration and expansion of lighting control technology are the integration of a new generation of highspeed networks and intelligent digital dimming equipment. Light network control system generally consists of special equipment and general equipment, professional equipment generally includes access to the system conventional light console, scanner console, color changer console and other general equipment including Ethernet switches and personal computers. Professional control equipment through the network interface, you can directly access the network system, you can also access a DMX / network conversion device through the DMX interface, and then access the network system. At this time, you can control signals through the network to any place you want, Then the network signal demodulated into DMX signals to control dimming cabinets, computer lights, color changers and other equipment.

Acoustics is a specialized, comprehensive technology that studies the conversion, recording, transmission and replay of sound signals. Digital audio technology refers to the sound technology, based on the acoustic signal after a series of digital processing, and then restoring high-quality analog sound signal technology. Digital audio technology has been deep into all aspects of everyday life, from home theater, car audio to personal music player, which all reflect the superiority of digital audio. With the continuous development of information technology, digital audio technology continues to develop and innovate, and its core and key technologies continue to be improved, making the audio industry digital and intelligent with good prospects.

\section{A CASE Study of ACOUSTiC Sound System DESIGNING FOR THE OPENING CEREMONY OF THE 9TH UNIVERSIADE}

Due to the special nature of the activity, the reliability of the system is of the utmost importance to the designer. To ensure success, the overall sound reinforcement is composed of three systems of master, preparation and podium. Its basic structure is:

Use three completely independent pieces of sound reinforcement equipment, one for master and two for work simultaneously. Main PA system work, the backup system equipment are all in working condition, but the main mixer dual output signal bypass, the backup speaker does not sound, once the main system problems, the backup system automatically cut into the work, which is also used The advantages of digital technology equipment. The main system uses the audience GB Class A cloth sound program, powered by the stadium on the 2 nd transformer. Standby system using the stadium's original voice PA speakers plus independent microphones and audio sources, by hand and the main system synchronization control, and by the No. 3 transformer power supply; once the main system has any failure (including power), the scene can be seamless connection. At the same time, the installed independent third system (podium system) also works synchronously, powered by the backup generator. Even in the main system of all problems (including two power failure), the scene can still be normal activities.

The main system uses a multi-channel surround sound design program:

Design index: The maximum sound pressure level: The average sound pressure level in the frequency band of 100$6300 \mathrm{~Hz} \geq 103 \mathrm{~d} \mathrm{~B}$; The transmission frequency characteristic: The average sound pressure level in $100-6300 \mathrm{~Hz}$ is $0 \mathrm{~d} \mathrm{~B}$, in this frequency band allows $\leq \pm 4 \mathrm{~d}$ B; Transmission Gain (d B): $100-6300 \mathrm{~Hz}$ Average $\geq-8 \mathrm{~d}$ B SPL; Sound field nonuniformity (d B): $100 \mathrm{~Hz} \leq 10 \mathrm{~d} \mathrm{~B} 1000 \mathrm{~Hz}, 6300 \mathrm{~Hz} \leq 8 \mathrm{~d} \mathrm{~B}$; Noise: The sound reinforcement system does not produce obvious and perceptible noise interference; Language clarity $\geq 85 \%$.

To ensure high quality, safe and stable transmission, mixed audio signals, the main system selected a Digico SD9 digital mixer (YAMAHA M7CL optional backup system). The console is stable, easy to operate, and its own design with equalizer, pressure limiter, delay, exciter and backup power supply, is currently preferred for use on-site version of the device. The source used to multichannel audio workstations to consider for replay of the surround sound. At the same time with TASCAM professional broadcast MDbased home-based backup. Traditional sound reinforcement projects have to use a lot of peripherals, connection and debugging is extremely complex. After applying the digital technology, the system control is completely solved by several groups of processors, reducing the intermediate links and reducing the failure rate.

\section{CONCLUSION}

Dance design is a serious art with great creativity. It is worth our constant exploration. Russia drama stage art design in its deep culture of moisture and masters of the adherence and constant innovation, has exudes a charming fragrance, reflecting the long-lasting vitality, today still has a vast mass market, engaged in the practice of the United States and the study of the Artists, Russian theater stage art design is still a treasure, it is worth our constant study and reference.

\section{REFERENCES}

[1] Wu Guangyao. Manuscripts on western drama history [M] Beijing: China Theater Press, 2002.

[2] Shen Yao Ding stage art design practice and skills [M] Beijing: Beijing Arts and Crafts Press, 2004.

[3] Wang Hong, Chen Xiaoshen, Zhang Xingjian. Digital technology and new media communication, Communication University of China Press, August 2010, first edition.

[4] Li Sida. Digital media art design, Tsinghua University Press, September 2009, first edition. 
[5] Wang Xiaomeng. The impact of the digital age on modern Chinese art design, Art and Technology, 2013-08.

[6] Qu Guowu. A variety of "art space" - on 2012 CCTV Spring and night light and light design, Modern Television Technology, 2012-03. 